\title{
Femoral sheath removal after cardiac catheterization in the Jordanian hospitals: An explorative study
}

\author{
Asma M. Haj-Hassan ${ }^{1}$, Ayman M. Hamdan-Mansour ${ }^{2 *}$, Ruqayya S. Zeilani ${ }^{3}$, Manar M. Nabolsi ${ }^{3}$ \\ ${ }^{1}$ Department of Clinical Nursing, Faculty of Nursing, The University of Jordan, Amman, Jordan; asma.alhaj@ju.edu.jo \\ ${ }^{2}$ Department of Community Health Nursing, Faculty of Nursing, The University of Jordan, Amman, Jordan; \\ ${ }^{*}$ Corresponding Author: a.mansour@ju.edu.jo \\ ${ }^{3}$ Faculty of Nursing, The University of Jordan, Amman, Jordan; r.Zeilani @ju.edu.jo, manarn@ju.edu.jo
}

Received 20 June 2012; revised 2 August 2012; accepted 14 August 2012

\section{ABSTRACT}

Objectives: The purpose of this study was to investigate the methods of sheath removal (femostop, compressor and manual compression) among Jordanian patients post cardiac catherization. Material and Methods: A descriptive explorative design utilized to collect data from 87 patients underwent cardiac catherization. Data collected on demographics, health remarks and complication pre and post cardiac catherization and in relation to sheath removal methods and complications. Results: The majority of the patients $(94.2 \%, n=80)$ had a manual sheath removal compared to $1 \%(n=1)$ compression and $7 \%(n=6)$ had femostop method. Kruskal-Wallis $\mathrm{H}$ test revealed there were significance difference in PTT and ACT reports in relation to type of procedures $(0.24, p 0.015 ; 0.32, p=0.005$ respectively). However, there were no significant differences between methods of sheath removal methods in relation to pain level, MAP before, MAP after, and heart rate with $p$ value $>0.05$. Patient's age had negative association with HR after the procedure (BTAU $=-0.19, p=0.02)$, while no significant differences found in post catherization complication (hematoma and pain level) and all other health remarks $(p>0.05)$ in regards to patients' age and gender. Moreover, patients' MAP readings were significantly different in relation to number of rest hour that patients had post cardiac catherization $(p=0.049)$. Conclusion: The study found that most patients and health professionals preferred manual removal methods of sheath post cardiac catherization. Cardiac health professionals, has to consider health remarks and demographic characteristics of their patients when planning care for their patients and more research needed to explore these issues.

Keywords: Cardiac Catherization; Jordan; Sheath Removal

\section{INTRODUCTION}

Invasive diagnostic tests and interventions including right and left heart catheterization are becoming routine diagnostic tools in cardiology departments worldwide. The procedure includes insertion of sheaths where femoral and radial arteries are the sites for sheath insertion. However, femoral sheath is the most common site of insertion for the sheath. The procedure may have some adverse effects and possible complications, in which femoral hematoma after femoral angiography or intervention consider a common one [1]. According to Berry and associates [1] up to $41 \%$ of patients underwent percutaneous coronary procedures developed femoral hematoma. The normal haemostatic response to vessel damage depends on interaction between vessel walls and circulating platelets and coagulation factors. It has been found that use of small diameter catheters (5 FR) has been associated with successful immediate post procedural sheath removal and early discharge [2]. The current literature suggests that time to homeostasis after sheath removal is shorter with manual compression than with mechanical assisted compression devices [3]. Lehman and Associates [3] reported that bleeding was lower among patients who underwent manual compression (3\%) and clamp compression (4\%) than among those with pneumatic compression (16\%). Formerly, removal of femoral sheaths after cardiac interventional procedures is done by physicians. Recently, removal of sheaths has become a role of cardiac nurses [4]. Peet and colleagues [5] emphasized the initial priorities for nursing care for clients after Percutaneous Coronary Intervention (PCI) 
that include determining physiology stability and patient comfort, through combining bed side assessment and use of monitoring technology. Therefore, cardiac nurses knowledge and competency related to effective measures used to prevent pot PCI complication considered a quality indicator issues. To achieve homeostasis after sheath removal, cardiac nurses are required to recognize that various techniques can be used to manage post PCI complications [5]. This will enable them to better decide the best methods and provide a quality nursing care for their patients. However, the literature has no consensus on the best methods that can be used to prevent post sheath removal complications. For example, hematoma expected to occur following manual compression after pressure dressing removal that results in impairing blood perfusion to lower limbs, and may lead to series of complication such as psudoaneurysm formation and acute peripheral arterial occlusion [6,7]. It has been found that the time required attaining homeostasis (measured in minutes) using the quicklamp compression device was significantly longer as compared to manual compression [6,7]. Moreover, no statistical significance difference found in pain level during application of either manual compression or quicklamp compression [6]. Previous studies showed that some devices have transparent domes that provide direct visualization of the puncture site during compression, while others use pneumatic or clamp pressure that is less intensive than manual compression [8]. The removal of femoral sheath includes initial assessment, serial monitoring of the vital signs, oxygen saturation, and peripheral pulses. The recognition and initial treatment of vascular complications is often a nursing responsibility, and yet, there is dearth of information available in the literature discussing this issue.

The increasing number of cardiac catheterizations procedures in outpatient settings, the desire for earlier mobilization of patients, and efforts to decrease vascular injury and complications led to the development and use of alternative haemostatic devices such as mechanical clamps, inflatable devices and manual pressure $[9,10]$. Jordanian institution use all advanced methods in sheath removal, however; evaluation of effectiveness in terms of complications has not been addressed in the Jordanian literature. This study came to address this issue and more to explore and compare the conventional methods used at the Jordanian health setting. The purpose of this study was to investigate the methods of sheath removal (femostop, compressor and manual compression) among Jordanian patients post cardiac catherization. The specific aims were:

1) To investigate the use of various methods of sheath removal, femostop, compressor and manual compression procedures, among Jordanian patients post cardiac catherization?
2) To examine if there is any differences in post sheath removal related to sheath removal method and demographic and personal characteristics of Jordanian patients post cardiac catherization?

\section{METHODS}

\subsection{Design}

This study utilized descriptive-explorative design to investigate sheath removal methods post cardiac catherization among Jordanian Patients. Data collected using structured observational methods from three main health center in Jordan that provide cardiac catherization care to Jordanian patients indicated for cardiac catherization.

\subsection{Sample and Setting}

A convenience sample of 87 patients underwent cardiac catherization procedure have agreed to participate in the study during the period of August to November, 2010. Inclusion criteria included: 1) to be 18 years or above, and 2) planned to undergo one of the three cardiac catherization procedures. Exclusion criteria included patient with cognitive impairment or unconscious. Patients were recruited from three healthcare centers that are known to provide specialized cardiac catherization care for the Jordanian and non-Jordanian patients. The three health care centers are located in the capital city of Jordan, Amman.

\subsection{Data Collection Procedure}

Prior data collection, ethical approval obtained from the Academic research committee at the Faculty of Nursing and Deanship of Academic Research at the University of Jordan. Principal investigator contacted the targeted health centers and obtained their approval for conducting the study. A facilitator was assigned at each health center to facilitate approaching patients and obtained their approval to participate in the study. Facilitator approached the patients who met the inclusion criteria and invited them to participate in the study. Those who agree approached by the principal investigator (PI). PI explained the purpose of the study, its significance, and what is required from patients if they agree to participate. Those who expressed interest in participation were given a consent form to sign. The consent form included all information about the study; purpose, significance, benefits, risks, and procedures. Patients were also assured of confidentiality and privacy of information and that no one but the research team will have access to the data. The consent form included a statement states clearly that their participation is voluntarily and they have the right to withdraw at anytime. Data collected by trained cardiac nurses of the same institution. Nurses trained by the principal investigator. Data collection took place simultaneously at the three health centers from first August, to 
November, 2010.

\subsection{Ethical Consideration}

Approval of the Academic Research Committee at the Faculty of Nursing, Deanship of Academic Research and the targets institutions represented the ethical approval to conduct the study. Patients approached firstly by facilitator assigned by the institution and then by the investigators. Consent form signed prior data collection.

Participants were assigned an identification number at the beginning of the study and all information was kept confidential by the investigators. All files were kept in locked cabinets at the Faculty of Nursing, University of Jordan. The electronic versions of the project and its data were kept in the primary investigator's computer.

\subsection{Instrumentation}

Data collected using an adapted structured form designated to describe and measure post-sheath removal intervention developed by Lehman [3] and Pracyk [11]. The measures includes information related to change in skin color (acchymosis) and consistency of the area around the puncture site in axial dimensions for around $20 \mathrm{~cm}^{2}$ (see appendix 1). The measure has been translated by a professional English language editor and all information presented in Arabic language in concurrent with medical terminologies. The measure pilot tested for understandability and check for feasibility and applicability.

In addition, covariates obtained using an author-developed profile of demographic and personal characteristics of patients. This includes information about age, gender, diagnosis, procedure, catheter size, catheter material, anti coagulation and antiplatelet drugs (heparin, aspirin, plavix) body mass index, glycoprotein $1 \mathrm{~b}$ lla receptor inhibitor, length of stay at hospital, prior cardiac catherization.

\subsection{Data Analysis}

The statistical package for social science (SPSS 17, Inc., Chicago, Illinois) was utilized for analysis. Variables described by using the central tendency measures (means, and medians) and the dispersion measures (standard deviation and ranges). Pearson correlation coefficient (r) used to examine the relationship between the variables. t-test and ANOVA, or chi-square have been used to examine difference in methods of sheath removal in relation to demographic and personal characteristics of the patients.

\section{RESULTS}

\subsection{Demographic Characteristics}

Mean age of patients was 58.5 years $(\mathrm{SD}=12.9)$ and their age ranged from 33 to 83 years. Of them, $72.4 \%$ (n $=63)$ were males and $27.6(n=24)$ were females. Mean age for female patients was $64.3(\mathrm{SD}=2.2)$ while mean age for male patients was $56.4(\mathrm{SD}=1.6)$. Among the 87 patients, $50.6 \%(\mathrm{n}=44)$ recruited from university-affiliated hospital and $49.4 \%$ (43) were from private sector.

\subsection{Health Remarks}

The first research question was to examine the various methods of sheath removal. The analysis (see Table 1) showed that among the 87 patients participated in the study, $44.8(n=39)$ are scheduled for cardiac catherization, $42.5 \%(n=37)$ scheduled for stent, 6.9\% $(n=6)$ scheduled for PTCA, and 5.8\% $(\mathrm{n}=5)$ others. Mean of Body Mass Index (BMI) was $28.3(\mathrm{SD}=4.7)$ and ranged from 19 to 49.0. BMI for male patients was 27.8 (SD = 0.61) while for female patients BMI was 29.8 (SD = $0.79)$. About $68.9 \%(n=60)$ of the patients had their procedure done from $8 \mathrm{AM}$ to noon while the others $(31.1 \%, \mathrm{n}=27)$ had their procedure done from noon to 15:30 PM. The majority of the patients $(91.9 \%, \mathrm{n}=80)$ had a manual sheath removal compared to $1.1 \%(\mathrm{n}=1)$ compression and $6.9 \%(n=6)$ had femostop method.

Table 1. Descriptive characteristics of patients post cardiac catherization $(\mathbf{n}=87)$.

\begin{tabular}{|c|c|c|c|c|c|}
\hline Variable & & $\mathbf{M}$ & SD & $\mathbf{N}$ & $\%$ \\
\hline Age & & 58.5 & 12.9 & & \\
\hline \multirow{2}{*}{ Gender } & Male & & & 63 & 72.4 \\
\hline & Female & & & 24 & 27.6 \\
\hline \multirow{2}{*}{ Health sector } & $\begin{array}{l}\text { University } \\
\text { affiliated }\end{array}$ & & & 44 & 50.6 \\
\hline & Private & & & 43 & 49.4 \\
\hline \multirow{4}{*}{ Procedure } & Cardiac Cath & & & 39 & 44.8 \\
\hline & Stent & & & 34 & 39.1 \\
\hline & PTCA & & & 6 & 6.9 \\
\hline & Others & & & 5 & 5.8 \\
\hline $\begin{array}{c}\text { Sheath removal } \\
\text { procedure }\end{array}$ & $\begin{array}{l}\text { Manual } \\
\text { Compressor } \\
\text { Femostop }\end{array}$ & & & $\begin{array}{c}80 \\
1 \\
6\end{array}$ & $\begin{array}{c}94.2 \\
1.0 \\
6.9\end{array}$ \\
\hline $\begin{array}{l}\text { Post cath. rest } \\
\text { time }\end{array}$ & $\begin{array}{c}8 \mathrm{hrs} \text { rest } \\
6 \mathrm{hrs} \text { rest } \\
5 \mathrm{hrs} \text { rest } \\
1 \mathrm{hr} \text { rest }\end{array}$ & & & $\begin{array}{c}21 \\
61 \\
1 \\
3\end{array}$ & $\begin{array}{r}24.4 \\
71.0 \\
1.2 \\
3.5\end{array}$ \\
\hline Heparin & $\begin{array}{c}\text { None } \\
5000 \mathrm{iu} \\
5000-10000 \mathrm{iu} \\
>1000 \mathrm{iu}\end{array}$ & & & $\begin{array}{c}34 \\
3 \\
14 \\
29\end{array}$ & $\begin{array}{c}48.8 \\
3.8 \\
16.3 \\
33.7\end{array}$ \\
\hline $\begin{array}{l}\text { Antiplatelet } \\
\text { agent post cath. }\end{array}$ & $\begin{array}{l}\text { None } \\
\text { Tritace }\end{array}$ & & & $\begin{array}{c}81 \\
4\end{array}$ & $\begin{array}{c}94.3 \\
4.7\end{array}$ \\
\hline Inhibitors & $\begin{array}{c}\text { None } \\
\text { Before } \\
\text { Before and after }\end{array}$ & & & $\begin{array}{c}77 \\
4 \\
2\end{array}$ & $\begin{array}{c}90.0 \\
4.7 \\
2.3\end{array}$ \\
\hline
\end{tabular}


All patients of manual sheath removal used size 6 FR of sheath. The majority of them $(70.1 \%, n=61)$ had 6 hours of rest compared to $24.1 \%(\mathrm{n}=21)$ had 8 hours rest. Only $1.2 \%(\mathrm{n}=1)$ and $3.5 \%(\mathrm{n}=3)$ had 5 hours and 2 hours of rest, respectively. About 39.0\% $(\mathrm{n}=34)$ patient did not receive heparin, while $33.3 \%(n=29)$ received 10,000 iu or more. About 3.8\% $(\mathrm{n}=3)$ and $16.1 \%$ $(\mathrm{n}=14)$ of them had $5000 \mathrm{iu}$ and 5000 to $10,000 \mathrm{iu}$, respectively. Most of the patients $(60.9 \%, \mathrm{n}=53)$ received a combination of acetylsalicylic acid and plavix in the catherization laboratory, while $16.3(n=14)$ did not receive anti-platelet agent at all. Post catherization, 93.1 (n $=81$ ) did not receive antiplatelet agent compared to $4.7 \%$ $(n=4)$ who did receive tritace. Regarding type and timing of administration of inhibitor, the analysis showed that the majority of patients $(88.5 \%, \mathrm{n}=77)$ did not receive inhibitors at any time before, during or after the procedure. Four patients $(4.6 \%)$ received inhibitors after procedure, and two patients $(2.3 \%)$ received inhibitors during and after the procedure.

Moreover, the analysis (see Table 2), homodynamic reading (heart rate and mean arterial blood pressure) were more stabilized and have lower score post cardiac catherization procedure. This corresponds with appearance of complications, as more than $94 \%$ of the patients had no complications at all compared to only $5.0 \%$ of them who had hematoma. Data analysis also showed that the majority of the pain had very mild level of pain as about $70 \%$ of them had a score of $0-3$ on the visual analogue scale of pain.

\subsection{Effectiveness of Methods of Sheath removal}

To test for the difference in the effectiveness between the manual sheath removal and other methods, chisquare test revealed a non-significant difference in relation to rhythm before and after catherization and sheath removal with $\mathrm{p}$ value $>0.05$.

Kruskal-Wallis $\mathrm{H}$ test revealed there were significance difference in PTT and ACT reports in relation to type of procedures $(0.24, \mathrm{p} 0.015 ; 0.32, \mathrm{p}=0.005$ respectively). However, there were no significant differences between methods of sheath removal methods in relation to pain level, MAP before, MAP after, and heart rate with $\mathrm{p}$ value $>0.05$. Regarding differences in complications related to health remarks, the analysis showed (see Table 3) that patients with larger BMI had positive association with MAP before (BTAU $=0.19, \mathrm{p}=0.041$ ) and negative association with PTT $(\mathrm{BTAU}=-0.24, \mathrm{p}=$ 0.015). Pain has been associated with heparin dose, PTT reading, and time of complication observed $(p>0.05)$, while bleeding has been associated with heart rate, MAP, and type of thrombolytic agent $(p>0.05)$. Moreover, patients' MAP readings were significantly different in relation to number of rest hour that patients had post cardiac catherization $(p=0.049)$. To examine the effect of the size of used sheath, the analysis showed that patients were significantly different in relation to HR before the procedure (chi-square $=17.2, \mathrm{p}<0.001$ ), and HR after the procedure $($ chi-square $=16.4, \mathrm{p}<0.001)$.

Table 2. Descriptive of health remarks before and after catherization of patient undergo sheath removal $(n=87)$.

\begin{tabular}{|c|c|c|c|c|c|}
\hline \multicolumn{2}{|c|}{ Variable } & \multicolumn{2}{|c|}{ Before } & \multicolumn{2}{|c|}{ After } \\
\hline & & $\mathbf{n}$ & $\%$ & $\mathbf{n}$ & $\%$ \\
\hline \multirow[t]{2}{*}{ Lidocaine } & Yes & & & 86 & 98.9 \\
\hline & No & & & 1 & 1.1 \\
\hline \multirow[t]{3}{*}{ Heart rate } & $<80$ & 61 & 70.1 & 68 & 78.2 \\
\hline & $81-120$ & 25 & 28.7 & 17 & 19.5 \\
\hline & $>120$ & 1 & 1.1 & 1 & 1.2 \\
\hline \multirow[t]{2}{*}{ Rhythm } & Regular & 85 & 97.7 & 86 & 98.9 \\
\hline & Irregular & 2 & 2.3 & 1 & 1.2 \\
\hline \multirow[t]{4}{*}{$\begin{array}{c}\text { Mean arterial } \\
\text { pressure }\end{array}$} & $40-60$ & 2 & 2.3 & 0 & 0 \\
\hline & $61-80$ & 19 & 21.8 & 24 & 27.6 \\
\hline & $81-99$ & 37 & 42.5 & 42 & 48.3 \\
\hline & $\geq 100$ & 29 & 33.3 & 21 & 24.1 \\
\hline \multirow[t]{3}{*}{ Pain level } & $0-3$ & & & 59 & 67.8 \\
\hline & $4-6$ & & & 19 & 21.8 \\
\hline & $7-10$ & & & 9 & 10.3 \\
\hline \multirow[t]{3}{*}{$\begin{array}{c}\text { Time of } \\
\text { complication }\end{array}$} & None & & & 82 & 94.3 \\
\hline & $\begin{array}{l}\text { Immediately after } \\
\text { sheath removal }\end{array}$ & & & 4 & 4.6 \\
\hline & $\begin{array}{l}\text { After sheath removal } \\
\text { and before dressing }\end{array}$ & & & 1 & 1.2 \\
\hline \multirow[t]{2}{*}{ Complications } & None & & & 82 & 94.2 \\
\hline & Hematoma & & & 5 & 5.7 \\
\hline
\end{tabular}

Table 3. Bivariate analysis of types of sheath removal and post catherization complications in relation to demographic and health remarks $(n=87)$.

\begin{tabular}{cccc}
\hline & Variable & \multicolumn{2}{c}{ Test statistics } \\
\hline \multirow{2}{*}{ Hematoma } & MPA post cath. & BTAU & p-value \\
& HR post cath. & -0.22 & $\mathbf{0 . 0 4 4}$ \\
Pain level & Heparin dose & 0.22 & $\mathbf{0 . 0 2 9}$ \\
& PTT post cath. & 0.24 & $\mathbf{0 . 0 2 3}$ \\
& Time of complication & 0.049 \\
observed & & 0.65 & $\mathbf{0 . 0 1 4}$ \\
Method of & ACT post cath. & 0.32 & $\mathbf{0 . 0 0 5}$ \\
sheath removal & PTT post cath. & 0.24 & $\mathbf{0 . 0 1 5}$ \\
\hline
\end{tabular}


Related to demographic characteristics, the analysis showed that patient's age had negative association with $\mathrm{HR}$ after the procedure (Kendall's tau $\mathrm{b}=-0.19, \mathrm{p}=$ 0.02 ), while no significant association found between age and post catherization complication (hematoma and pain level) and all other health remarks $(p>0.05)$. In regards to gender, the analysis showed that there were no significant differences in post catherization complication complication (pain level and hematoma) and other health remarks $(\mathrm{p}>0.05)$.

\section{DISCUSSION}

The purpose of this study was to investigate the effectiveness of using various methods of sheath removal among patient post cardiac catherization. In Jordan, it is important to mention that the literature emphasized the expected high cost spent to manage complication of invasive cardiac interventions [12], in spite of development of evidence-based guideline for PCI [13]. The results, in general, showed that manual sheath removal is the most used method as about $95 \%$ of them had this method. One possible explanation is that patients and health professsional preferred the manual removal methods for its lowest cost compared to other methods. However, in relation to post sheath removal complications and factors that influence post sheath removal, this study found that about $95 \%$ of the patients had no complication at all and that all patients $(100 \%)$ had used a small gauge of sheath (6 FR). the results corresponds with previous international studies that found a positive association between using small size and successful immediate post procedural sheath removal and early discharge [2,14]. The results, however; do not correspond with previous study who reported a $41 \%$ incidence of hematoma post sheath removal [1]. This study reported only about $6 \%$ of the patients had hematoma. This indicates that the successfulness of sheath removal measured by complications such as hematoma and early discharge or mobilization has to be considered cautiously. For example, manual sheath removal required bed rest for longer period that mechanical and invasive ones. In this study $95 \%$ of the patient had to rest for at $6 \mathrm{hrs}$ post sheath removal. This would indicate that the post sheath complication such hematoma has been influence by the longer period of bed rest, therefore; only $5 \%$ of the patients had hematoma.

Bleeding as a complication has been reported for neither patient with manual sheath removal nor invasive ones. The results do not correspond with previous international study who reported lower bleeding report incidence among patient post manual sheath removal those other methods [3]. One explanation for this incorrespondence related to less number of patients who had nonmanual sheath removal (only $7 \%$ ) that make is difficult to compare, and another explanation is the report of no bleeding among all patients in this study. Another inconsistent report with previous international study is related to time of the occurrence of hematoma or complication. In this study, and among the only $5 \%$ of hematoma cases, $4.7 \%$ had the complication immediately after sheath removal and less that $1 \%$ before dressing. While, Jones and Mccutcheon [5] maintained that hematoma expected to occur following manual compression after pressure dressing removal. The results would be explained in consideration of the methods of sheath removal and the lengthy period of bed rest following sheath removal. In addition, the study found that patient's age and weight had a significant role in post cardiac catherization complication, and patients' Mean Arterial Pressure readings were significantly different in relation to number of rest hour that patients had post cardiac catherization and significantly different in relation to heart rate before and after the procedure.

\section{CONCLUSION AND IMPLICATIONS}

The study has implication for health professional concerned about patients undergoing cardiac catherization. The study found that most patients and health professsionals preferred manual removal methods of sheath post cardiac catherization. In addition, the study found that sheath removal resulted in very low incidence of hematoma, and there are differences in health remarks post sheath removal related to demographic characteristics. This indicates that health professional, particularly cardiac health professionals, has to consider health remarks and demographics characteristics of their patients when planning care for those patients post cardiac catherization. Moreover, here is a need to have the health professional discuss options available for sheath removal to improve discharge criteria. In this study the majority of the patients had to rest for at least six hours post sheath removal. The cost effectiveness quality of care and the evidence based practice guidelines requires health professionals to adapt innovative methods that are cost effective. A variety of factors can influence the choice of which method to use, including the physician's preference, ability to successfully deploy the device, cost, and patient-specific factors such as peripheral vascular disease and use of anticoagulation. Although all methods are comparable in terms of safety and effectiveness, the literature (Hamel, 2009) shows that mechanical methods of sheath removal associated with quicker homeostasis and ambulation. More research needed to investigate the patients and health professionals' preference of methods of sheath removal and to explore health professionals' knowledge and practices related to post cardiac catherization care, and factors that influence patients' decision 
and choice related to methods of sheath removal.

\section{REFERENCES}

[1] Berry, C., Kelly, J., Cobbe, S.M. and Eteiba, H. (2004) Comparison of femoral bleeding complications after coronary angiography versus percutaneous coronary intervention. American Journal of Cardiology, 94, 361-363.

[2] Zeller, T., Frank, U., Muller, C., Burgelin, K., Sinn, L., Bestehorn, H.P., Cook-Bruns, N. and Neumann, F. (2003) Predictors of improved renal function after percutaneous stent-supported angioplasty of severe atherosclerotic ostial renal artery stenosis. Circulation, 108, 2244-2249. doi:10.1161/01.CIR.0000095786.44712.2A

[3] Lehmann, K.G., Heath-Lange, S.J. and Ferris, S.T. (1999) Randomized comparison of homeostasis techniques after invasive cardiovascular procedures. American Heart Journal, 138, 1118-1125. doi:10.1016/S0002-8703(99)70078-5

[4] Capasso, V., Conder, C., Meuller, G. and Bouvier, S. (2006) Peripheral arterial sheath removal program: A performance improvement initiative. Journal of Vascular Nursing, 24, 127-132. doi:10.1016/j.jvn.2006.09.001

[5] Peet, G.I., McGrath, M.A., Brunt, J.H. and Hilton, J.D. (1995) Femoral arterial sheath removal after PTCA: A cross-Canada survey. Canadian Journal of Cardiovascular Nursing, 6, 13-19.

[6] Jones, T. and Mccutcheon, H. (2003) A randomized controlled trial comparing to obtain homeostasis following coronary angiography. Intensive and Critical Care Nursing, 19, 11-20. doi:10.1016/S0964-3397(03)00005-3

[7] Benson, L., Wunderly, D., Perry, B., Kabboord, J., Wenk, T., Birdsall, B., Vanderbos, L., Roach, V., Goole, R., Crippen, C., Nyirenda, T., Rumsey, L. and Manguba, G. (2005) Determining best practice: Comparison of three methods of femoral sheath Removal after cardiac interventional procedures. Heart \& Lung, 34, 115-121. doi:10.1016/j.hrtlng.2004.06.011

[8] Nordrehaug, J.E., Chronos, N.A., Priestley, K.A., Buller, N.P. and Foran, J. (1996) Randomized evaluation of an inflatable femoral artery compression device. Journal of Interventional Cardiology, 9, 381-387. doi:10.1111/j.1540-8183.1996.tb00645.x

[9] Kussmaul, W.G., Buchbinder, M., Whitlow, P.L., Aker, U.T., Heuser, R.R., King, S.B., Kent, K.M., Leon, M.B., Kolansky, D.M. and Sandza, G.G. (1995) Rapid arterial hemostasis and decreased access site complications after cardiac catheterization and angioplasty: Results of a randomized trial of a novel hemostatic device. Journal of the American College of Cardiology, 25, 1685-1692. doi:10.1016/0735-1097(95)00101-9

[10] King, N., Philpott, S. and Leary, A.B. (2008) A randomized controlled trial assessing the use of compression versus vasoconstriction in the treatment of femoral hematoma occurring after percutaneous coronary intervenetion. Heart \& Lung, 37, 205-210. doi:10.1016/j.hrtlng.2007.05.008

[11] Pracyk, J.B., Wall, T.C., Longabaugh, J.P., Frank, D., Tice, F.D., Hochrein, J., Green, C., Cox, G., Lee, K., Stack, R.S. and Tcheng, J.E. (1998) A randomized trial of vascular hemostasis techniques to reduce femoral vascular complications after coronary intervention. American Journal of Cardiology, 81, 970-976. doi:10.1016/S0002-9149(98)00074-5

[12] Kugelmass, A.D., Cohen, D.J., Brown, P.P., Simon, A.W., Becker, E.R. and Culler, S.D. (2006) Hospital resources consumed in treating complications associated with percutaneous coronary interventions. American Journal of Cardiology, 97, 322-327. doi:10.1016/j.amjcard.2005.08.047

[13] Weitz, J.I., Hirsh, J. and Samama, M.M. (2008) American College of Chest Physicians. New antithrombotic drugs: American College of Chest Physicians evidence-based clinical practice guidelines (8th Edition). Chest, 133, 234S-256S.

[14] Hoeper, M., Lee, S., Voswinckel, R., Palazzini, M., Jais, X., Marinelli, A., et al. (2006) Complications of right heart catheterization procedures in patients with pulmonary hypertension in experienced centers. Journal of the American College of Cardiology, 48, 2546-2552. doi:10.1016/j.jacc.2006.07.061 